Trab. Ling. Aplic., Campinas, 50(1): 75-95, Jan./Jun. 2011

\title{
O LIVRO DIDÁTICO IMPORTADO DE INGLÊS E O ENSINO DA ESCRITA
}

\author{
THE IMPORTED ENGLISH TEXTBOOK AND THE TEACHING OF WRITING
}

\author{
MARÍLIA MENDES FERREIRA*
}

\begin{abstract}
RESUMO: O texto analisa como a série Interchange, terceira edição, conceitua escrita e seu ensino e se a abordagem de ensino dessa habilidade muda ao longo da série. Os exercícios do livro foram classificados em cinco categorias e concluiu-se que a escrita, de modo geral, foi concebida como demonstração de conhecimento gramatical e de vocabulário, como uma prática mecânica de uso da língua descontextualizada, padronizada e prescindível de modelos ou amostras. O ensino da escrita assumido pelo material adota uma abordagem inferior à tradicional e o material procura uma atualização teórica e mercadológica com a inserção de técnicas da abordagem processual e com a etiquetagem de textos com termos referentes aos gêneros textuais.

Palavras-chave: livro didático; ensino da escrita; gênero textual
\end{abstract}

\begin{abstract}
The paper analyses how the textbook series Interchange, third edition, conceptualizes writing, writing instruction and if the latter changes as the series moves along. The exercises of the book were classified into five categories and it was possible to conclude that overall writing was conceived as a mere opportunity for grammar and vocabulary practice, as a mechanical decontextualized practice of language, not based on models or samples. The writing instruction adopts a worse procedure than the traditional perspective and the material seeks theoretical and market update through the insertion of process writing techniques and through labeling texts with genre names.
\end{abstract}

Keywords: textbook; writing instruction; genre

\section{INTRODUÇÃO}

O livro didático (LD) de língua estrangeira (LE) tem sido analisado sob diferentes aspectos e perspectivas teóricas (ALMEIDA FILHO et al, 1991; CORACINI, 1999; GAFFUR e MENEGASSI, 2009; PEREIRA, 2000; XAVIER e URIO, 2006). Em particular, gostaria de me deter nos estudos sobre o tratamento da escrita no LD. Podese observar, pela experiência em sala de aula, que o ensino de línguas negligencia essa habilidade, na medida em que ela é relegada aos momentos finais da aula e às partes finais da unidade do LD e dada como atividade extraclasse, não sendo merecedora de um momento da aula para ser trabalhada detalhadamente. Possivelmente, esse é um dos motivos pelos quais os alunos acabam desenvolvendo uma visão deturpada da escrita. Ela é concebida como prática gramatical ou vocabular (GAFFURI e MENEGASSI, 2009; RAIMES, 1991; WARSCHAUER, 2000) ${ }^{1}$, na qual noções como audiência e objetivos sociais vinculados ao ato de escrever não são abordados e portanto, desconhecidos mesmo

\footnotetext{
*USP, São Paulo (SP), Brasil. mmferreira@usp.br

${ }^{1}$ Rojo (2009) relata situação semelhante em relação ao ensino do português como L1.
} 
pelos alunos mais proficientes ${ }^{2}$. $\mathrm{O}$ ensino da escrita acaba sendo regido pelo princípio tácito de que o conhecimento da leitura conduzirá à aprendizagem da escrita; ou ainda, essa habilidade não é necessária, já que escrever pode ser um dom (BONINI, 2002 apud ROJO, 2009). Portanto, a escrita não é vista como uma atividade social realizada discursivamente.

Além disso, diante de um mundo altamente globalizado e regido pela economia do conhecimento, o uso da LE não somente na forma oral, mas também na escrita ${ }^{3}$, mostrase cada vez mais necessário (WARSCHAUER, 2000). Portanto, faz-se premente refletir sobre a atividade (ENGESTROM, 1987; LEONTIEV, 1981) de ensino desta habilidade no Brasil e sobre o LD como um instrumento nesse processo. Juswick et al (2006), em um estudo sobre pesquisas na área da escrita entre os anos de 1999 e 2004, reconhecem essa importância no mundo atual ao afirmar que ela é "um imperativo econômico" (p.452). Warschauer (2000) cita um exemplo da necessidade da escrita como meio de inserção numa comunidade discursiva. Um pesquisador não nativo do inglês somente conseguiu ter seu nome entre os coautores do trabalho a ser publicado através do auxílio de um professor da língua para redigir um email. Assim, a escrita precisa não somente ser mais valorizada pela área de ensino de inglês como língua estrangeira, mas também pelos LDs, já que constituem um instrumento mediador poderoso do processo de aprendizagem ${ }^{4}$ ao oferecer caminhos para seu ensino.

Como parte de um projeto maior que busca investigar a atividade do ensino da habilidade de escrita em inglês em diferentes $\operatorname{contextos}^{5}$, o presente trabalho se propõe a analisar um material didático importado (a série Interchange publicada pela Cambridge University Press, terceira edição) amplamente utilizado no Brasil, segundo informações de grandes distribuidoras do país coletadas por telefone por essa autora. A análise enfoca a concepção de escrita do material, a concepção de ensino dessa habilidade, e se essa concepção se altera nos livros mais avançados da série. Esse último tópico foi investigado por se supor que os alunos, em um nível avançado de proficiência em inglês, receberiam um ensino da escrita também mais avançado. Através dessa análise, objetiva-se investigar a gênese da escrita em LE e, com essas informações, contribuir para se refletir sobre o ensino dessa habilidade e se criar mecanismos para a melhora de seu ensino.

\section{FUNDAMENTAÇÃO TEÓRICA}

Os estudos sobre a escrita em inglês como segunda língua/LE (a distinção desses termos aqui não será feita) datam da década de 70 e inicialmente, confirmaram resultados

${ }^{2}$ Tenho verificado este fato nos cursos de escrita ministrados aos alunos ingressantes nos cursos de Letrashabilitação inglês da universidade onde trabalho.

${ }^{3} \mathrm{O}$ surgimento da internet alterou a natureza da escrita, como mostram os estudos em multiletramentos, porém a necessidade se escrever em nossa sociedade, seja de modo mais ou menos multimodal, é inegável.

${ }^{4}$ Não defendo que o LD seja o único recurso utilizado pelo professor para o ensino da LE, mas sabe-se que em muitos contextos de ensino no Brasil essa é a realidade, infelizmente. (PEREIRA, 2000; XAVIER e URIO, 2006)

5 Atualmente, uma aluna de iniciação científica investiga como uma escola de idiomas ensina esta habilidade. O objetivo do projeto é expandir a investigação para outros contextos como os cursos de letras, por exemplo e sobre a motivação dos alunos de escola pública para trabalharem essa habilidade. 
Trab. Ling. Aplic., Campinas, 50(1), Jan./Jun. 2011

das pesquisas da escrita do inglês como língua materna (LM) (ZAMEL;1976; 1982; 1983). Esses estudos em LM investigaram o processo de composição do texto, as estratégias do aluno para escrever e sugeriram intervenções pedagógicas para o ensino da escrita (EMIG, 1971; PERL, 1980; SOMMERS, 1982; SQUIRE e APPLEBEE, 1969). Posteriormente, os estudos da escrita em inglês como LE passaram a testar a eficiência das estratégias dos alunos (FERRIS, 1997; SPACK, 1984; ZAMEL, 1985).

Pode-se dizer que há três perspectivas de ensino da escrita do inglês como LE e como LM: uma abordagem tradicional, a perspectiva processual e uma perspectiva social, baseada em gêneros textuais. A perspectiva dos multiletramentos (KRESS, 2003) redefine escrita, submetendo-a à lógica do espaço e da imagem, porém, não apresenta uma proposta de ensino desta forma de escrita.

Conforme nos reporta Zamel (1976), a abordagem tradicional, também denominada abordagem de foco no produto, foi fortemente influenciada pelo behaviorismo. A partir desta teoria psicológica, os seguintes princípios para o ensino da escrita em LE surgiram: (a) a escrita é formação de hábito (imitando os modelos de texto), (b) escrever é uma habilidade que não se ensina (GRABE e KAPLAN, 1996), e (c) proficiência em gramática, automaticamente, conduz a uma boa escrita. Em decorrência desses princípios a prática pedagógica consistia em reforçar o bom comportamento na escrita, através de modelos de textos a serem imitados e uma ênfase na correção gramatical para se evitar o reforço desse erro, visto como um mau hábito. A instrução enfatiza os recursos que levam à produção de um texto considerado perfeito: gramática e ortografia, a reformulação de frases problemáticas, a transformação de frases curtas para outras mais complexas, e o foco sobre o tópico frasal e sobre os padrões para a construção da introdução, desenvolvimento e conclusão do texto. Pode-se concluir que a escrita consiste numa ocasião para a prática de gramática e para a exibição de seu conhecimento. Embora este tipo de ensino ainda possa ser encontrado atualmente, esta abordagem foi utilizada principalmente entre 1940 e 1960 (KERN, 2000).

Em oposição à abordagem tradicional, surgiu a perspectiva processual (em inglês denominada de process writing) por volta da década de 70. Esta perspectiva se iniciou com os estudos de Squire e Applebee (1969) e Emig (1971) sobre o ensino de inglês como LM nas escolas inglesas e estadunidenses, respectivamente. Seus princípios são os seguintes: (a) foco na criatividade e expressão pessoal de ideias, em vez de um foco na forma (por exemplo, sob a forma de diários); (b) os temas de interesse dos alunos são privilegiados; (c) espaço maior para livre expressão de ideias e emoções no texto e na aula; (d) a rejeição de exercícios artificiais dos livros de ensino da escrita; (e) o foco na poesia; (f) muito estímulo para que os alunos escrevam; (g) instrução implícita de gramática; (h) a ausência de intervenção do professor na escrita dos alunos; (i) uma audiência constituída da esfera pública em vez de somente a interação professor-aluno; e (j) conferências do professor com o aluno em que há mais foco na forma, aspectos retóricos do texto e reformulações (SQUIRE e APPLEBEE, 1969). Nesta perspectiva, a escrita é vista como uma ocasião para a expressão da criatividade do aluno (ELBOW, 1981; MURRAY, 1968; 1980; 1985) enquanto que, para a sua vertente cognitivista, ela consiste num meio de investigação desta criatividade através de modelos cognitivos (FLOWER e HAYES, 1977; 1980; 1981). 
A vertente criativa ofertou à área uma série de atividades que se consagrou como técnicas eficazes para o ensino da escrita em inglês tanto como LM quanto como LE: atividades de pré-escrita e de desenvolvimento de ideias (brainstorming, diários, respostas a perguntas) conferências, reescritura do texto. Deve-se ressaltar que a abordagem processual almeja o produto final bem escrito tanto quanto a abordagem tradicional; a diferença repousa no meio de se atingir tal fim. Enquanto aquela foca no processo, esta se concentra no produto.

Apesar de haver diferentes escolas de gêneros textuais com diferentes conceituações do termo, a escrita, para todas, constitui-se numa atividade social. Marcuschi (2008) descreve várias linhas de estudo de gêneros textuais, entretanto, limito-me a discutir quatro escolas de gêneros influentes tanto no Brasil quanto no exterior: a australiana (MARTIN, 1991, 1993), o interacionismo sociodiscursivo (BRONCKART, 2003; SCHNEUWLY et al, 2004), a nova retórica (BAZERMAN, 2005; FREEDMAN e MEDWAY, 1994; MILLER, 1984) e a swaliana (SWALES, 1990; 2004). Na tabela a seguir, o conceito de gênero e a proposta pedagógica das linhas são expostos:

Tabela 1 - O conceito de gênero textual e propostas de ensino nas diferentes linhas

\begin{tabular}{|c|c|c|}
\hline Linha & Conceito & Proposta pedagógica \\
\hline australiana & $\begin{array}{l}\text { "processos sociais orientados por um } \\
\text { objetivo que se concretiza por meio de } \\
\text { estágios" }{ }_{6}\end{array}$ & $\begin{array}{l}\text { Roda (apresentação, } \\
\text { conjunta de construção } \\
\text { independente de textos, } \\
\text { ZAMMIT, 1994) }\end{array}$ \\
\hline $\begin{array}{l}\text { interacionismo } \\
\text { sociodiscursivo }\end{array}$ & $\begin{array}{l}\text { Não há (MACHADO, 2005) } \\
\text { Textos/ gêneros são considerados } \\
\text { instrumentos mediadores do agir humano na } \\
\text { atividade social } \\
\text { Foco de análise: tipos de discurso, tipos de } \\
\text { sequência, e operações linguísticas (coesão, } \\
\text { nominalização, modalização, escolhas } \\
\text { lexicais) (MACHADO, 2005) }\end{array}$ & $\begin{array}{l}\text { Sequências didáticas (apresentação da } \\
\text { situação, produção inicial, avaliação } \\
\text { do nível das capacidades de linguagem } \\
\text { do aluno pelo professor, módulos } \\
\text { (exercícios), produção final (DOLZ et } \\
\text { al, 2004) }\end{array}$ \\
\hline nova retórica & "ação social"” & $\begin{array}{l}\text { Não há (FREEDMAN, 1994) } \\
\text { Gêneros não podem ser ensinados, mas } \\
\text { somente aprendidos na prática }\end{array}$ \\
\hline swaliana & $\begin{array}{l}\text { "uma classe de eventos comunicativos cujos } \\
\text { membros compartilham um conjunto de } \\
\text { objetivos. Estes objetivos são reconhecidos } \\
\text { pelos membros mais experientes da } \\
\text { comunidade discursiva e constituem a razão } \\
\text { do gênero" } 8\end{array}$ & $\begin{array}{l}\text {-elaboração de material didático } \\
\text { (SWALES e FEAK, 2000, 2004) } \\
\text {-desenvolvimento de consciência } \\
\text { retórica } \\
\text {-identificação de movimentos e passos } \\
\text { obrigatórios e optativos }\end{array}$ \\
\hline
\end{tabular}

${ }^{6}$ Tradução minha para "staged-goal oriented social processes" (MARTIN,1993, p. 142)

${ }^{7}$ Traduação minha para "social action" (MILLER, 1984, p. 15)

${ }^{8}$ Tradução minha para "a class of communicative events, the members of which share some set of communicative purposes. These purposes are recognized by the expert members of the parent discourse community, and thereby constitute the rationale of the genre" ( SWALES, 1990, p. 58). Em texto posterior (ASKHAVE e SWALES, 2001), os autores destacam a complexidade do objetivo comunicativo do gênero, conferindo uma maior importância ao contexto para a sua identificação. 
O percurso desses três momentos de conceituação da escrita e de seu ensino revelam que o contexto social vai sendo inserido paulatinamente e que o movimento processual permanece principalmente na forma de técnicas (escrita em conjunto, reescrita). O ensino de aspectos formais é retomado nos gêneros textuais, porém de uma forma contextualizada e resignificada. Enquanto que na perspectiva tradicional, escreve-se para demonstrar conhecimento gramatical, no gênero de trabalho com a forma, seja ele no nível linguístico, seja no nível da macroestrutura (movimentos e passos), é sempre contextualizado pela audiência, pelo objetivo do gênero, pela resposta retórica a ações sociais recorrentes que ele representa. ${ }^{9}$

Em suma, o ensino com os gêneros textuais, independentemente da escola, implica numa visão de língua como prática social, num reconhecimento de que ilustram um conflito básico constitutivo da língua - a relação dialética entre regras e criatividade, entre estabilidade e instabilidade -, que constituem manifestações (concretizações) discursivas e culturais, que o seu ensino pressupõe um trabalho com textos autênticos (i.e. não simplificados) em sala de aula e a exploração dos aspectos sociais constitutivos do texto. Sobretudo, o ensino com os gêneros textuais implica reconhecer que eles não são fórmulas, mas, sobretudo, um tipo de conhecimento sobre o funcionamento linguístico e, portanto, constitutivo do letramento, juntamente com outros tipos de conhecimento.

Faz-se necessário analisar a concepção de língua dessas abordagens. Pelo exposto acima, pode-se deduzir que a perspectiva tradicional se apoia em uma visão estruturalista de língua ("um sistema de regras que defende a autonomia do sistema diante das condições de produção" (MARCUSCHI, 2008, p. 59). Já a abordagem processual não adota uma visão de língua, talvez por não possuir um embasamento teórico consistente (GRABE e KAPLAN, 1996). Pode-se hipotetizar que a concepção seja instrumentalista, já que a escrita é um instrumento de transmissão de informações (MARCUSCHI, 2008), no caso, a expressão da criatividade e também uma atividade cognitiva ("ato de criação e expressão do pensamento típica da espécie humana”, MARCUSCHI, 2008, p.59). As abordagens de gêneros textuais adotam uma visão sócio-histórica da língua ("a língua é um sistema de práticas sociais e históricas sensíveis à realidade sobre a qual atua, sendo-lhe parcialmente prévio e parcialmente dependente esse contexto em que se situa" (MARCUSCHI, 2008, p.61) $)^{10}$.

\section{METODOLOGIA}

Diante dos avanços nas reflexões sobre o conceito de escrita e de seu ensino, procurei analisar o LD Interchange para responder às seguintes perguntas de pesquisa: 1) que concepção de escrita essa coleção apresenta?; 2) qual concepção de ensino da escrita

${ }^{9}$ Bakhtin (1986) também trata da questão dos gêneros, denominado por ele de gêneros do discurso. Sua definição fundamenta as escolas aqui descritas. Entretanto, por não apresentar uma proposta pedagógica, mas somente de análise de gêneros (conteúdo, estilo verbal e construção composicional), optei por não classificá-lo como uma perspectiva de gênero textual.

${ }^{10} \mathrm{O}$ ISD, por considerar o gênero como um instrumento psicológico (VYGOTSKY, 1987) para o desenvolvimento de capacidades linguísticas, adquire também uma conotação cognitiva de língua, mas não da mesma filiação que o gerativismo ou a psicologia cognitiva americana. 
- tradicional, processual (ZAMEL, 1976) ou baseada em gêneros - ela possui?; 3) as concepções de escrita e seu ensino mudam ao longo da série?

Os quatro livros da série foram analisados - intro e livros 1,2,3 - nas versões do aluno e do professor. Primeiramente, todos os exercícios que envolviam o ato de escrever, fossem eles denominados pela coleção de exercícios de gramática, de escuta, ou propriamente de escrita, foram computados e classificados conforme taxionomia a ser exposta posteriormente. A contagem não se restringiu aos exercícios puramente de escrita, por se verificar que ela também estava presente em outros exercícios, associados a outras habilidades, como a oral, por exemplo. Portanto, optou-se por analisar o material como um todo. O critério utilizado para essa taxionomia foi a função exercida pela escrita nos exercícios. Essa função, na análise, revela a relação dos exercícios com as abordagens da escrita discutidas anteriormente.

\section{RESULTADOS}

Seguindo a metodologia descrita, os exercícios foram classificados em cinco tipos definidos a seguir: A) Mecânico: o exercício não é de escrita propriamente dito, mas requer do aluno que escreva para ser realizado. Os exercícios compreendem tomar notas em um exercício de escuta, preencher lacunas com informações como horas, dias, números ou elaborar perguntas para respostas já dadas. O livro didático, no índice, classifica esses exercícios como de escrita. Por esse motivo, eles foram considerados, também aqui. como tais. Esses exercícios não exigem construção de textos, seja no nível da sentença ou além dela, e de sentidos, com um objetivo social e para uma audiência definida. A escrita se estabelece e se inicia na palavra ou na sentença isolada, privada de um contexto social maior; ela se faz presente somente na coordenação motora e por isso o adjetivo mecânico foi utilizado. $\mathrm{O}$ fato de o LD considerar tais exercícios como sendo de escrita sinaliza uma concepção limitada da mesma que perpassa todo o material, como se observa mais adiante. Essa denominação indica, também, uma estratégia mercadológica dos autores. Como no livro Intro os alunos não possuem condições de escrever parágrafos ou textos mais longos, classificar exercícios desse tipo como de habilidade escrita, no índice, revela que o material cumpre sua função de ensinar a LE nas quatro habilidades (ver anexo1).

B) Mediador: o exercício objetiva utilizar a escrita para facilitar a realização de um exercício oral ou de fixação da pronúncia. O primeiro objetivo citado foi mais comum. $\mathrm{Na}$ verdade, essa prática é bastante frequente em aulas de LE, principalmente nos estágios iniciais; o professor permite que alunos escrevam seus diálogos antes de os apresentarem. O índice não os classificou como exercício de escrita. (ver anexo 2)

C) Instrumento de treino gramatical ou vocabular: o exercício objetiva, primeiramente. praticar algum item gramatical ou um conjunto de palavras ensinadas na unidade. De certo modo, todos os exercícios no LD possuem esse objetivo, mas o que os faz estar nessa classificação e não nas outras é possuir o objetivo primeiro e não subliminar de praticar a gramática. A maioria dos exercícios sob essa categoria se encontram na parte 'grammar focus' do livro (ver anexo 3). Eles não são classificados como de escrita pelo autor.

D) Instrumento de prática oral: o exercício possui, como objetivo principal, oferecer um 
contexto para a prática oral do aluno. Deve-se esclarecer que a diferença entre esse tipo e o B seria que aqui a atividade tem seu desenho afetado para auxiliar a prática da oralidade. Por exemplo, o aluno deve omitir informações no texto produzido para gerar uma lacuna de informação no momento da prática oral ou mesmo escrever partes do texto em diferentes pedaços de papel. Em suma, a finalidade maior é a prática oral e não a escrita. (ver anexo 3 ). Os exercícios não são também classificados como de escrita pelo LD.

E) De escrita propriamente dito: o objetivo maior do exercício consiste em promover a escrita e o autor do livro o intitula como um exercício de escrita. Isso não quer dizer que a tarefa não objetive praticar também gramática ou que a atividade não possa ser integrada com a prática oral (ver anexo 5).

A tabela a seguir mostra a quantidade dos tipos de exercícios presentes na coleção:

Tabela 2 - Quantidade dos tipos de exercícios nos livros da coleção

\begin{tabular}{|c|l|l|l|l|l|l|l||}
\hline LIVRO & EXERCÍCIO & $\mathbf{A}$ & $\mathbf{B}$ & $\mathbf{C}$ & $\mathbf{D}$ & $\mathbf{E}$ & TOTAL \\
\hline \multirow{2}{*}{ Intro } & $\begin{array}{l}7 \\
(21.2 \%)\end{array}$ & $\begin{array}{l}11 \\
(33.333 \%)\end{array}$ & $\begin{array}{l}5 \\
(15.1 \%)\end{array}$ & $\begin{array}{l}5 \\
(15.1 \%)\end{array}$ & $5(15.1 \%)$ & 33 \\
\hline \multirow{2}{*}{1} & $\begin{array}{l}0 \\
(0 \%)\end{array}$ & $\begin{array}{l}9 \\
(25.7 \%)\end{array}$ & $6(17,1 \%)$ & $8(22.8 \%)$ & $\begin{array}{l}12 \\
(34.3 \%)\end{array}$ & 35 \\
\hline \multirow{2}{*}{2} & $\begin{array}{l}1 \\
(2.04 \%)\end{array}$ & $\begin{array}{l}10 \\
(20.41 \%)\end{array}$ & $\begin{array}{l}16 \\
(32.65 \%)\end{array}$ & $\begin{array}{l}8 \\
(16.33 \%)\end{array}$ & $\begin{array}{l}14 \\
(28.57 \%)\end{array}$ & 49 \\
\hline \multicolumn{2}{|l|}{3} & $\begin{array}{l}5 \\
(11.11 \%)\end{array}$ & $\begin{array}{l}22 \\
(48.88 \%)\end{array}$ & $\begin{array}{l}2 \\
(4.44 \%)\end{array}$ & $\begin{array}{l}16 \\
(35.55 \%)\end{array}$ & 45 \\
\hline
\end{tabular}

Os tipos $\mathrm{A}$ e $\mathrm{C}$ se enquadram numa abordagem tradicional, enquanto que $\mathrm{B}$ e $\mathrm{D}$ não se enquadram em nenhuma perspectiva de ensino da escrita, pois concebem a escrita como facilitadora de outras habilidades (fala e pronúncia). Não houve exercícios que estimulassem a criatividade do aluno e sua expressividade, tal como advoga a abordagem processual. O tipo E poderia encaixar-se na abordagem de gêneros, mas, como se verá posteriormente, o LD não consegue fazê-lo adequadamente e nem se propõe a isso.

A tipologia dos exercícios e sua quantidade revelam a concepção de escrita da coleção (pergunta 1). O tipo mecânico esteve mais presente no primeiro livro da série (Intro), provavelmente por ser o início do curso e obviamente menos proficiência poderia ser exigida para se escrever textos mais complexos. O tipo $\mathrm{C}$ (treino linguístico) aparece em maior número no livro 3. Isso pode ter ocorrido por esse volume abordar vários itens gramaticais complexos como modais, pronomes relativos e uso do gerúndio e infinitivo. Frequentemente, o LD pedia que fossem feitas sentenças isoladas para se treinar essas estruturas. Quanto aos números do exercício tipo E, eles aumentaram na proporção em que se evoluía o curso. No livro 2, ainda aparece um exercício do tipo A (mecânico). Este exercício consiste em tomar notas de mensagens deixadas na secretária eletrônica. Ele foi considerado um exercício de escrita pelo livro ${ }^{11}$.

${ }^{11}$ Reproduz-se a seguir o exercício da p. 110 do livro 3 da série em análise. "Writing a voice mail message - Dan is out of town for the weekend. Listen to four voice mails he received. His roommate has written down the first message. Write down the three other messages." 
Se se somar os números das categorias $\mathrm{B}$ e $\mathrm{D}$, que subordinam a escrita à prática oral, pode-se concluir que o material está priorizando esta habilidade em detrimento daquelafato que se verifica também nos slogans das propagandas das escolas de idiomas.

De modo geral, o LD em questão concebeu a escrita como demonstração de conhecimento gramatical e de vocabulário, como uma prática descontextualizada, padronizada do uso da língua e prescindível de modelos ou amostras de textos. Digo prescindível porque a grande maioria dos exercícios tipo E não disponibilizava aos alunos amostras reais do texto a ser escrito ou, quando o fazia, eles eram incompletos; somente seu início era provido.

$\mathrm{O}$ aspecto treineiro e mecânico da escrita advém de uma visão desta habilidade como uma atividade descontextualizada. Não havendo uma audiência para os textos e nem um objetivo social para escrevê-los, o objetivo mais palpável ao aluno e ao professor torna-se o da prática gramatical, que pode ocorrer na modalidade oral (na forma de drills por exemplo) ou na forma escrita. Em suma, a escrita acaba sendo não uma atividade merecedora de atenção na aula, para que se lide com suas especificidades, mas sim uma mera ação motora de colocar sentenças ilustrativas do ponto linguístico em questão no papel. De modo menos robusto, a escrita foi concebida como uma habilidade associada ou em função da fala.

Em resposta à pergunta 2 (qual a concepção de ensino da escrita - tradicional, processual (ZAMEL, 1976) ou baseada em gêneros - ela possui?) pode-se afirmar que a coleção filia-se teoricamente à abordagem tradicional. Entretanto, como operacionalização dessa abordagem, o LD adota uma postura pré-tradicional, pois o trabalho com o texto é de qualidade inferior à abordagem tradicional. Os modelos são incompletos. Quando os há, não há trabalho com o tópico frasal, e tampouco a transformação das frases mais simples para as mais complexas. Ou seja, na abordagem tradicional se vislumbra o trabalho com o texto e seu aperfeiçoamento, diferentemente do que ocorre com a atividade proporcionada por este LD com a escrita.

Como atualização, o LD adota técnicas da abordagem processual de modo tímido e os nomes de gêneros textuais não apresentam tratamento dos textos como tais. Em alguns momentos, o manual do professor sugere que se utilizem técnicas como brainstorming ${ }^{12}$ e revisão em pares $^{13}$. Porém, possivelmente essas técnicas não serão empregadas pelo professor devido à falta de tempo. Como se sabe, a escrita geralmente é a última das habilidades a ser focada e não se reserva um tempo de sala de aula para seu trabalho. $\mathrm{O}$ professor, que opera frequentemente em um calendário apertado, muito provavelmente não adota esses procedimentos em aula. Como consequência, o alunado não tem oportunidade de experimentar um ensino da escrita como processo, ou seja, como reescritura, como uma ação que se realiza em vários rascunhos que devem ser revistos por ele mesmo, pelo colega e pelo professor. Pode-se concluir que tais técnicas estão presentes no manual como sugestões e como atualizações teóricas do material. Ele sinaliza ao consumidor que está atualizado teoricamente com as tendências mais modernas do ensino, mas isso não

\footnotetext{
12 "Ss brainstorm ideas for a letter. They can work individually, or, if they are going to write about the same city's traffic problems, in pairs or small groups." (Manual do professor, livro 2, p. 10)

13 "Ss exchange stories and read them aloud. Encourage Ss to ask follow-up questions and give additional information whenever possible." (Manual do professor, livro 2, p. 80)
} 
Trab. Ling. Aplic., Campinas, 50(1), Jan./Jun. 2011

constitui o seu carro-chefe. Isso fica evidente também com uma outra tendência atual do ensino de línguas e principalmente da escrita: a abordagem baseada em gêneros textuais.

O LD, na medida em que a série caminha, aumenta o número de exercícios do tipo E (escrita propriamente dito) e os etiqueta associando-os aos gêneros textuais; em decorrência disso, o material adquire um aspecto de atualização e modernidade. O número de gêneros citados no índice do livro 1 foi 6 (anúncio procurando colega de quarto, um artigo de revista, uma carta de conselho, uma crítica sobre um restaurante, um artigo para um sítio na internet e uma proposta para uma festa), no livro 2, 10 (carta ao editor, receita culinária, anúncio de classificados, carta de sugestões, instruções, carta de apresentação, introdução para um guia de viagem, conto, crítica de um filme, carta de conselho) e no livro 3, 11 (e-mail, notícia, estória, panfleto turístico, carta de reclamação, carta ao editor, carta de conselho, biografia, carta de desculpas, anúncio de tv, declaração pessoal (personal statement). Deve-se esclarecer que em nenhum momento o LD utiliza o termo gênero textual, seja na versão do aluno, seja na versão do professor. Mas o fato de utilizar ,no índice e no material, termos que facilmente são associáveis a gêneros textuais, como os mencionados acima, pode-nos levar a inferir que os autores desejam promover essa associação.

Apesar dessa máscara de atualização, a concepção de escrita permanece como um exercício gramatical e vocabular na forma de textos. O índice vai paulatinamente aumentando o número de etiquetas de gêneros, mas em nenhum momento trata tais textos como tais: 1) não concebe linguagem, e por extensão a escrita, como prática social; 2) não há explicação do contexto social dos textos; 3) não há audiência clara ou explicação do que seja esse conceito; 4) não há objetivos claros para o texto a ser escrito; 5) a organização e o conteúdo são trabalhados através de perguntas ou da quantidade de parágrafos sugerida no manual do professor, ao invés do conceito de movimentos ou de comunidade discursiva; 6) os modelos são ora incompletos, ora ausentes, ora inadequados; 7) não há instruções de como o professor deve trabalhar esses gêneros; por exemplo, não se explica o que é um panfleto de turismo (livro 3), uma carta ao editor (livro 3), ou uma carta de apresentação (livro 2).

Para ilustrar a má qualidade dos modelos, analiso o gênero carta ao editor do livro 2. O texto não é mostrado integralmente ao aluno e também não consiste em um exemplar do que seja uma carta ao editor. A carta, parcialmente mostrada, consiste em uma carta de reclamação (complaint letter). O manual do professor utiliza este termo, enquanto o livro do aluno utiliza o termo "carta ao editor". Além disso, o LD não provê explicações do que seja nenhum desses dois gêneros textuais.

A carta ao editor consiste em uma reação (elogio, recusa, consternação, revolta, apoio ou até mesmo uma reclamação) do leitor a uma notícia publicada pelo editor de uma revista ou jornal. Ela pode até envolver uma reclamação, mas ela deve estar atrelada a uma notícia lida pelo leitor. $\mathrm{O}$ mesmo tom de reclamação sobre um problema desvinculado de uma notícia é reforçado no livro 3. No caso do gênero em questão, o LD ensina-o de maneira errônea, ou no mínimo, confusa. Tomei como base para análise cartas ao editor de revistas e jornais em inglês de grande circulação como Times Magazine, Newsweek, The Guardian, e The New York Times. Os autores do LD não esclarecem se tinham em mente um tipo bem específico de cartas ao editor em que a não referência a uma notícia poderia estar presente. 
O gênero textual "biografia" é ensinado duas vezes na série: livro 1 e livro 3. No primeiro caso, o gênero biografia é somente utilizado como pretexto para a prática do presente simples, já que o exercício está vinculado à seção 'Grammar Focus', onde tal forma está sendo ensinada. O modelo incompleto, fornecido aos alunos, é o seguinte: "My classmate is a student. She lives near the university. She studies fashion design. She has a part-time job in a ... “. Já o livro 3 apresenta parte de um texto sobre Jimmy Carter e questões que sinalizam uma definição do gênero biografia: "what is this person famous for?, how and when did he or she become famous?, what are his or her important achievements?". Entretanto, no manual do professor não há informações sobre a definição desse gênero, o seu papel social, a sua audiência, sobre quem escreve biografias, sobre quem, na sociedade, tem suas vidas colocadas como tema de biografias, sobre o conteúdo de uma biografia e sua organização. A respeito deste tema, o manual somente informa que. como opção, o aluno pode organizar seu texto em 'introduction', 'early life', 'later life', 'conclusion' (Manual do professor, livro 3, p. 66). Outro aspecto que se deve comentar é a qualidade da amostra. Como o texto é incompleto, não se sabe sua fonte e, portanto, se é uma amostra real, autêntica do gênero biografia ou se foi um texto elaborado pelos autores. Pode-se perceber que o tipo de texto ensinado (biografia ou carta ao editor) é somente uma etiqueta de atualização teórica e estratégia mercadológica desprovidas de um tratamento pedagógico adequado.

A escrita, como pretexto do exercício gramatical, está presente mesmo nos exercícios do tipo $\mathrm{E}$ com etiquetagem de gêneros. No manual do professor do livro 2, página 76 , exercício 12, onde o gênero introdução a um guia de viagem foi pedido aos alunos, o objetivo de aprendizagem é descrito assim: " escreva uma introdução para um guia usando a passiva no presente simples e vocabulário para discutir produtos" 14

Deve-se atentar para o fato de que o LD perdeu boas oportunidades de ensinar habilidades e estruturas linguísticas com os gêneros apresentados. Por exemplo, a argumentação poderia ser explorada nas cartas ao editor e nas cartas de reclamação, autopromoção nas cartas de apresentação (cover letters) e nas declarações pessoais (personal statements) e linguagem informal nas cartas de conselho.

As concepções de escrita e de seu ensino (pergunta 3) não se alteram de acordo com o nível de proficiência, como se pode perceber na análise anterior, do modo como certos gêneros foram tratados ao longo da série.

\section{DISCUSSÃO}

A discussão dessa análise divide-se em questionamentos e em sugestões para reversão do quadro descrito. As seguintes questões podem ser elaboradas: 1) Quais são as consequências para o aluno de ter um aprendizado da escrita como esse?; 2) Que ensino de LE precisamos para sobrevivermos no mundo globalizado, regido pela economia do conhecimento e que demanda habilidades como criatividade, adaptabilidade a diferentes situações, solução de problemas, manipulação, análise e acúmulo de informação e products".

14 "write an introduction to a guidebook using the simple present passive and vocabulary for discussing 
Trab. Ling. Aplic., Campinas, 50(1), Jan./Jun. 2011

estabelecimento de medidas de ação para resolver problemas (FRIEDMAN, 2006)?; 3) o LD é um instrumento viável em nossas aulas com essas exigências do mundo globalizado?; 4) Por que o autor principal que se denomina um linguista aplicado no seu site oficial e que publica também livros na área de metodologia não incorpora os avanços da área no seu LD?

Como consequência, o aluno exposto ao ensino de escrita aqui descrito aprende que a língua não existe para significar, para agir no mundo e sim para treinar formas gramaticais e vocabulário. Este ensino intensifica a noção de língua como uma entidade isolada e não como um elemento vivo da sociedade e manipulável pelo usuário. Como aponta Marcuschi (2008) os LDs não adotam tal visão de língua. Politicamente, isso é conveniente para os países falantes do inglês e produtores desses materiais que, através dos mesmos, garantem a manutenção da norma padrão do idioma (GRADDOL, 1997; PENNYCOOK,1994), salvaguardam-no da contaminação pelo World Englishes (RAJAGOPALAN, 2005) e mantém um tópico universal, global e imune a influências culturais ${ }^{15}$, assegurando assim um mercado mundial de venda. Acredito que a não atualização dos materiais didáticos importados quanto à concepção de língua não ocorre somente para preservar a norma padrão do inglês utilizada pelos países do centro (inner-circle) (KACHRU,1982), mas também para se manter uma condição de subordinação linguística dos países menos desenvolvidos e não falantes do inglês para com os do centro. ${ }^{16}$ Canagarajah (2002), discutindo especificamente as dificuldades de alunos ESL com a escrita, atenta para o fato grave de que o foco da linguística aplicada na deficiência linguística do aluno mascara problemas geopolíticos mais profundos.

\begin{abstract}
A atitude pode ser descrita assim: os escritores de países periféricos escrevem como escrevem porque ainda não possuem proficiência lingüística suficiente na nossa língua ou porque eles têm que mudar para a nossa cultura (...). Mas, se nós entendermos que muitas das diferenças no texto são resultados de condições materiais das comunidades, podemos perceber que alguns desses problemas estão relacionados a desigualdades geopolíticas. p. 107-108. ${ }^{17}$
\end{abstract}

Pode-se concluir, dessa passagem, que o ensino da escrita, como uma atividade asocial, adiscursiva e calcada numa visão de língua como estrutura, contribui, de maneira decisiva, para a manutenção da subordinação (se não for econômica, pelo menos linguística) de países periféricos em relação aos países do centro.

15 A gramática normativa de uma língua é mutável, porém bem menos suscetível a mudanças, principalmente provocadas por usuários menos autorizados - os falantes não nativos.

${ }^{16} \mathrm{Na}$ escrita acadêmica, o mito do nativo parece ainda ser forte. Há periódicos que somente aceitam o artigo caso ele tenha sido corrigido por um editor nativo. Veja o que diz o certificado de revisão de um artigo para um periódico da área de energia :[the article]" was edited for proper English language, grammar, punctuation, spelling, and overall style by one or more of the highly qualified native English speaking editors at American Journal Experts". Certificado concedido à autora por uma participante de sua pesquisa sobre redação acadêmica.

17 Tradução minha do trecho original em inglês: "The attitude can be described as follows: periphery writers compose the way they do because they are still trying to develop proficiency in our language or because they have to make a shift from their culture to ours;(...)But if we understand that many of the differences in the written product also result from the material conditions of the respective communities, we can perceive how some of these problems are implicated in geopolitical inequalities." 
As consequências não são sentidas somente pelo aluno, mas também pelo futuro professor de línguas. $\mathrm{O}$ aluno que vivencia tal aprendizagem compromete sua formação de futuro professor: aprende a língua como sentença isolada, prática gramatical e vocabular, escrita como uma atividade asocial, para depois se exigir dele que a ensine como prática social da forma sugerida nos documentos oficiais como PCNs e OCNs ${ }^{18}$.

Com as exigências do mundo globalizado, não creio que o LD e a padronização curricular que ele representa possam continuar sendo utilizados como o eixo norteador do ensino de LE. Warschauer (2000) já atentou para esse fato e sua proposta defende um ensino de LE baseado em projetos que incorporem o pensamento crítico e as novas tecnologias. Rojo (2009), em contexto de ensino de português, propõe a junção dos multiletramentos e letramentos críticos com uma perspectiva bakhtiniana de gêneros textuais.

$\mathrm{Eu}$ acrescentaria a essas sugestões, o ensino de gêneros textuais numa perspectiva conceitual (FERREIRA e LANTOLF, 2008; FERREIRA, 2005), ou seja, o ensino do gênero como um conceito (VYGOTSKY, 1987). O conceito, segundo Vygotsky, baseiase em princípios básicos que regem um fenômeno e não em traços superficiais frutos de uma observação empírica. Em outras palavras, conceber algo como um conceito (língua, escrita ou gêneros textuais, por exemplo) é fruto de um pensamento denominado teórico, que contrasta com o predominante pensar empírico da sociedade ocidental (DAVYDOV, 1988; HEDEGAARD, 2002).

O pensamento teórico busca captar a dialética - transformação, interconexão, oposição dos elementos contrários - constitutiva do mundo (ACTON, 1967). Ele capacita os alunos para a solução de problemas e o desenvolvimento da criatividade e da criticidade. Numa perspectiva conceitual de língua, as funções social (comunicativa) e reguladora (cognitiva, mediadora) (VYGOTSKY, 1987) da linguagem se relacionam dialeticamente. A língua não pode ser definida somente como prática social - isso seria considerar somente seu aspecto social comunicativo - mas também como um instrumento psicológico que medeia, regula essa prática desenvolvendo o ser humano cognitivamente também. Além disso, essa visão auxiliaria desvincular o ensino da escrita, através de gêneros textuais, da ideia de um retorno ao formalismo (SAWYER e WATSON, 1987).

Em relação à pergunta 4, pode-se hipotetizar que o autor, inserido numa lógica do mercado e numa política velada de manutenção do inglês padrão e de subordinação linguística, nega os avanços da linguística aplicada, ao mesmo tempo em que despreza o aluno de inglês como segunda língua ou LE e banaliza o conteúdo ensinado (PENNYCOOK, 1994).

\section{CONCLUSÃ̃o}

Em suma, este artigo objetivou analisar uma série de livro didático importado, amplamente utilizada no Brasil e de autoria de um linguista aplicado, concernente à concepção e ao ensino da escrita e à evolução do seu ensino ao longo da série. A análise revelou que o material apresenta-se bastante tradicional nessas concepções, favorecendo

\footnotetext{
${ }^{18}$ Parâmetros curriculares nacionais e Orientações Curriculares Nacionais. O último foi lançado em 2006 em substituição aos PCN's do ensino médio.
} 
uma situação de subordinação linguística de países menos desenvolvidos para com os mais desenvolvidos. Entretanto, o artigo também procurou, na literatura da linguística aplicada, alternativas para a criação e implementação de currículos de ensino de LE mais inovadores e democráticos que promovam uma aprendizagem de LE mais relevante e condizente às necessidades dos aprendizes.

\section{REFERÊNCIAS BIBLIOGRÁFICAS}

ACTON, H. B. (1967). Dialectical materialism. In: EDWARDS, P. (org.), The encyclopedia of philosophy Vol. 2. New York: The Macmillan Co and the Free Press. p. 389-397.

ASKEHAVE, I.; SWALES, J.M. (2001). Genre identification and communicative purpose: a problem and a possible solution. Applied Linguistics, v. 22, n. 2, p. 195-212.

ALMEIDA FILHO, J.C.P. de et al. (1991). A representação do processo de aprender no livro didático nacional de língua estrangeira moderna no $1 \circ$ grau. Trabalhos em Linguística Aplicada. v. 17, p. 67-97.

BAKHTIN, M.M. (1986). Speech genres and other late essays. Austin, TX: University of Texas Press.

BAZERMAN, C. (2005). Gêneros textuais, tipificação e interação. Org. Ângela P. Dionísio e Judith C. Hoffnagel,Trad. Judith C. Hoffnagel. São Paulo: Cortez.

BRONCKART, J.P. (1997). Atividade de linguagem, textos e discursos: por um interacionismo sócio-discursivo. Trad. Anna Raquel Machado e Péricles Cunha. São Paulo: EDUC, 2003.

CANAGARAJAH, S.A. (2002). A Geopolitics of Academic Writing. Pittsburgh, PA: University of Pittsburgh Press.

CORACINI, M.J. R.F. (1999). (org). Interpretação, Autoria e Legitimação do Livro Didático. Campinas: Pontes.

DAVYDOV, V. V. (1988). Problems of developmental teaching: the experience of theoretical and experimental psychological research. Soviet Education, v. 30, n.9, p. 3-83.

DOLZ, J.; et al. (2004). Sequências didáticas para o oral e a escrita: apresentação de um procedimento. In: SCHNEUWLY, B; et al. Gêneros Orais e Escritos na Escola. Trad. Roxane Rojo e Glaís S. Cordeiro. Campinas: Mercado de Letras, p. 95-147.

ELBOW, P. (1981). Writing with power. Oxford and New York: Oxford University Press.

EMIG, J. (1971). The composing processes of 12th graders. Urbana, Il: NCTE.

ENGSTROM, Y.(1987). Learning by expanding: an activity theoretical approach to developmental research. Helsinki: Orienta-Konsultit Ou.

FERRIS, D. (1997).The influence of teacher commentary on student revision. TESOL Quaterly, v. 31, n.2, p. 315-339.

FERREIRA, M.M. (2005). Concept-based Approach to Writing Instruction: from the Abstract Concept to the Concrete Performance. Tese de Doutorado. The Penn State University, EUA.

FERREIRA, M.M.; LANTOLF, J.P. (2008). A concept-based approach to teaching: writing through genre analysis. In: LANTOLF, J.P.; POEHNER, M.E. (orgs). Sociocultural Theory and the Teaching of Second Languages. London: Equinox, p. 285-320. 
FERREIRA - O livro didático importado de inglês

FLOWER, L.; HAYES, J. (1977). Problem solving strategies and the writing process. College English, v. 39, p. 365-387.

. (1980). The cognition of discovery: defining a rhetorical problem. College Composition and Communication, v. 31, p. 21-32.

. (1981). A cognitive process theory of writing. College Composition and Communication, v. 32, p. 365387.

FREEDMAN, A. (1994).'Do as I say’: The relationship between teaching and learning new genres. In: FREEDMAN, A.; MEDWAY, P. (orgs). Genre and the New Rhetoric. London: Taylor \& Francis, p. 191-210.

FREEDMAN, A.; MEDWAY, P. (orgs). (1994). Genre and the New Rhetoric. London: Taylor \& Francis, p. 191-210.

FRIEDMAN,T. L. (2006). The World is Flat. New York: Picador.

GAFFURI, P; MENEGASSI, R.J. (2009). Análise de atividades de leitura e escrita em língua inglesa em contextos de ensino diferenciados. Revista Querubim, v. 8, n.1, p. 138-149.

GRABE, W.; KAPLAN, R. B. (1996). Theory and practice of writing. Harlow, England: Longman.

GRADDOL, D. (1997). The future of English? London: British Council.

HEDEGAARD, M. (2002). Learning and child development: a cultural-historical study. Aarhus: Aarhus University Press.

JUSWICK, M.; et al. (2006). Writing into the $21^{\text {st }}$ century: an overview of research on writing, 1999 to 2004. Written Communication, v. 23, n. 4, p. 451- 476.

KERN, R. (2000). Literacy and language teaching. Oxford: Oxford University Press.

KACHRU, B. J. (1982). The other tongue: English across cultures. Urbana: University of Illinois Press.

KRESS, G. (2003). Literacy in the new media age. London: Routledge.

LEONTIEV, A. N. (1981). Problems of the development of the mind. Moscow: Progress.

MACHADO, A. R. (2005). A perspectiva interacionista sociodiscursiva de Bronckart. In: J.L.Meurer; A. Bonini; D.Motta-Roth (orgs). Gêneros: teorias, métodos, debates. São Paulo: Parábola Editorial, p. 237-259.

MARCUSCHI, L. A. (2008). Produção textual, análise de gêneros e compreensão. São Paulo: Parábola Editorial.

MARTIN, J. (1991). Intrinsic functionality: implications for contextual theory. Social Semiotics, v. 1, n. 1, p. 99-162.

. (1993). Genre and literacy: modeling context in educational linguistics. Annual Review of Applied Linguistics, v.13, p. 141-172.

MILLER, C. (1984). Genre as social action. Quaterly journal of speech, v. 70, p. 151-167.

MURRAY, D. M. (1968). A writer teaches writing: a practical method of teaching composition. Boston: Houghton Mifflin.

. (1980). Writing as process: how writing finds its own meaning. In: DONOVAN,T. McCLELLAND, B.(orgs.), Eight approaches to teaching composition Urbana, Il: National Council of Teachers of English, p. 3-20. 
Trab. Ling. Aplic., Campinas, 50(1), Jan./Jun. 2011

. (1985). A writer teaches writing. Boston: Houghton Mifflin.

MURRAY, N.; ZAMMIT, K. (1992). The action pack: Animals (Activities for Teaching Factual Writing). Sydney: Metropolitan East DSP.

PERL, S. (1980). A look at basic writers in the process of composing. In: KASEN, L. N.; HOEBER, D. R. (orgs.), Basic writing. Urbana, Ill: National Council of Teachers of English, p. 13-32.

PENNYCOOK, A. (1994). The cultural politics of English as an international language. London: Longman.

PEREIRA, A. L. (2000). O eurocentrismo nos livros didáticos de língua inglesa. Trabalhos em Lingüística Aplicada. v. 35 , p. 7-19.

RAJAGOPALAN, K. (2005). A geopolítica da língua inglesa e seus reflexos no Brasil. In: LACOSTE, Y.; RAJAGOPALAN, K. (orgs). A Geopolítica do inglês. São Paulo: Parábola Editorial, p. 135-159.

RICHARDS, J.; HULL, J.; PROCTOR, S. (2005). Interchange Intro. 3.ed. Cambridge. Cambridge University Press. . (2005). Interchange 1. . 3.ed. Cambridge. Cambridge University Press. (2005). Interchange 2. . 3.ed. Cambridge. Cambridge University Press. (2005). Interchange 3. . 3.ed. Cambridge. Cambridge University Press.

RAIMES, A. (1991). Out of the woods: emerging traditions in the teaching of writing. TESOL Quaterly. v. 25, p. 407-430.

ROJO, R. (2009). Letramentos Múltiplos, escola e inclusão social. São Paulo: Parábola Editorial.

SAWYER, W.; WATSON, K. (1987). Questions of genre. In: REID, I. (org). The place of genre in learning: current debates. Centre for Studies in Literary Education. Deakin University, p. 46-57.

SCHNEUWLY, B; et al. (2004). Gêneros Orais e Escritos na Escola. Trad. Roxane Rojo e Glaís S. Cordeiro. Campinas: Mercado de Letras.

SOMMERS, N. (1982). Responding to student writing. College Composition and Communication. v. 33, n. 2, p. $148-156$.

SPACK, R. (1984). Invention strategies and the ESL college composition student. TESOL Quaterly. v. 18, n. 4, p. $649-670$.

SQUIRE, J. R.; APPLEBEE, R. K. (1969). Teaching English in the United Kingdom. Champaign, Ill: NCTE.

SWALES, J. M. (1990). Genre analysis. Cambridge: Cambridge University Press. . (2004).Research Genres. Cambridge: Cambridge University Press.

SWALES, J.; FEAK, C. (2000). English in today's research world. Ann Arbor: The University of Michigan Press. . (2004). Academic Writing for Graduate Students. 2edição. Ann Arbor: The University of Michigan Press.

VYGOTSKY, L. S. (1987). The Collected Works of L. S. Vygotsky: v. 1. New York: Plenum.

WARSCHAUER, M. (2000). The changing global economy and the future of English teaching. TESOL Quaterly. v. 34 , n. 3 , p. 511-53. 
FERREIRA - O livro didático importado de inglês

XAVIER, R. P.; URIO, E. D. W. (2006). O professor de inglês e o livro didático: que relação é essa? Trabalhos em Linguística Aplicada. v. 45, n.1, p. 29-54.

ZAMEL, V. (1976). Teaching composition in the ESL classroom: what we can learn from research in the teaching of English. TESOL Quaterly. v. 10, n.1, p. 67-76. . (1982). Writing: the process of discovering meaning. TESOL Quaterly. v.16, n. 1, p. 67-76.

(1983). The composing processes of advanced ESL students: six case studies. TESOL Quaterly. v. 17, p. $165-187$. (1985). Responding to student writing. TESOL Quaterly. v. 19, p. 79-101.

\author{
ANEXO 1 \\ (é o exercício 11) \\ ANEXO 2 \\ (é o exercício 9) \\ ANEXO 3 \\ (é o exercício 3) \\ ANEXO 4 \\ (é o exercício 4) \\ ANEXO 5 \\ (é o exercício 12)
}

Recebido: 06/01/2010

Aceito: 02/04/2011 


\section{READING}

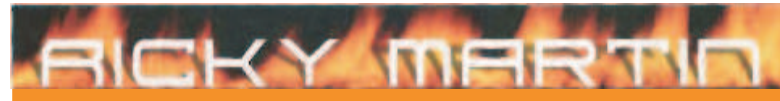

Scan the article. What three cities did Ricky Martin live in?

Dicky Martin was born in San Juan, Rerto Rico, on December 24, 1971 He was always a performer. As a child, he appeared in television commercials and studied singing.

At the age of 12 , he joined the Latin boy band, Menudo. He worked hard with them, and he became very well known. But he left the group after five years.

Martin moved to New York City, but he didn't work for a year. He was very frustrated, so he moved to Mexico City and got a part on a Mexican soap opera. Soon afterward, he recorded two Spanish-language albums. After this success, he moved back to the U.S.

Back in the U.S., he appeared on an American soap opera and in the Broadway show, Les Miserables. Then he made his first English-language album.

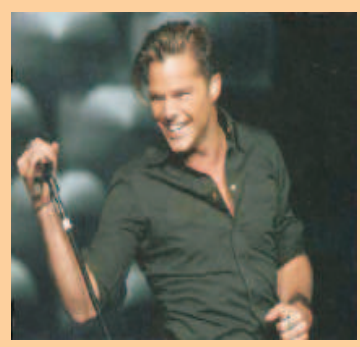

That album was called Ricky Martin. His biggest hit, "Livi n' La Vida Loca," wa on that album.

Now he's famous around the world. But he still works hard, and he still loves singing. As he said to a reporter for the newspaper USA Today: " want to do this forever."

\section{A Read the article. Then write a question for each answer.}

\begin{tabular}{|c|c|}
\hline 1 (1) & In Puerto Rico. \\
\hline 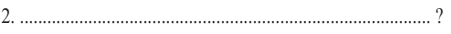 & At the age of 12 . \\
\hline 3. & After five years. \\
\hline 4. & Because he was frustrated. \\
\hline 5 & Les Miserables. \\
\hline 6 & "Livin’ La Vida Loca." \\
\hline
\end{tabular}

B Number these events in Ricky Martin's life from 1 (first event) to 10 (last event).

a. He joined a boy band.

f. He returned to the U.S.

b. He moved to New York City. g. He was born.

c. He made an English-language album.

h. He left Menudo.

d. He appeared in a Broadway musical.

i. He studied singing.

e. He recorded albums in Spanish.

j. He moved to Mexico.

C Group work Who is your favorite singer? What do you know about his or her life? Tell your classmates. 


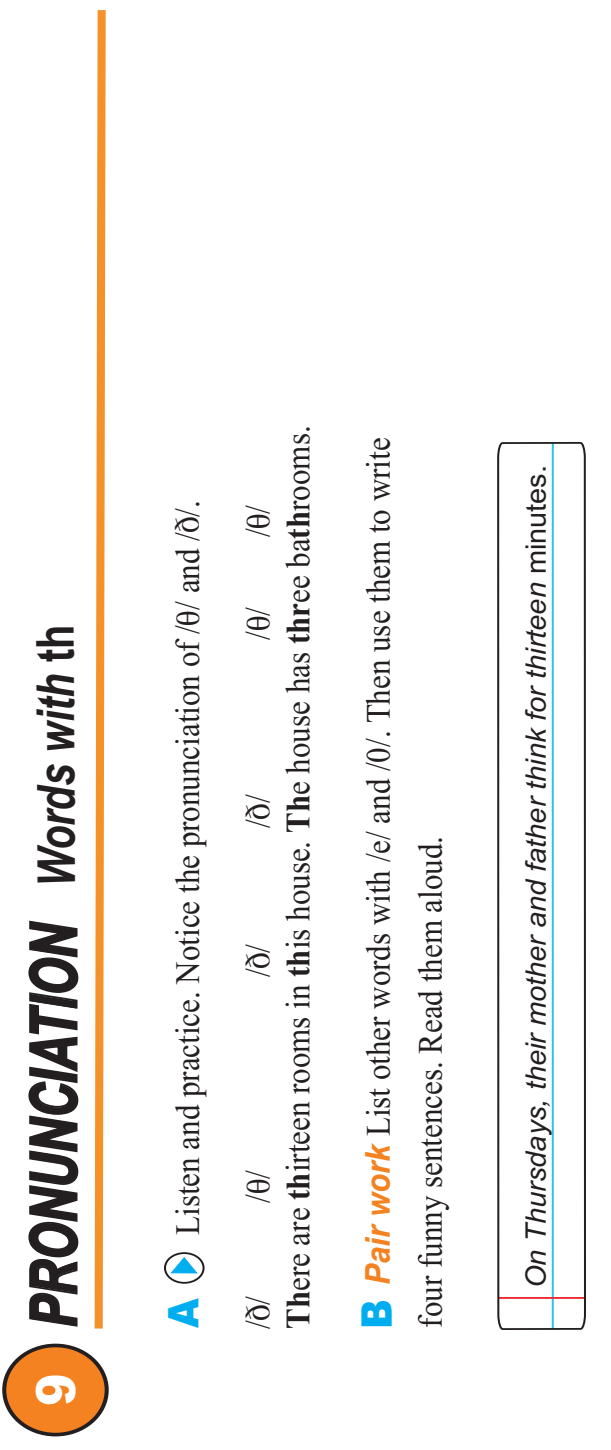



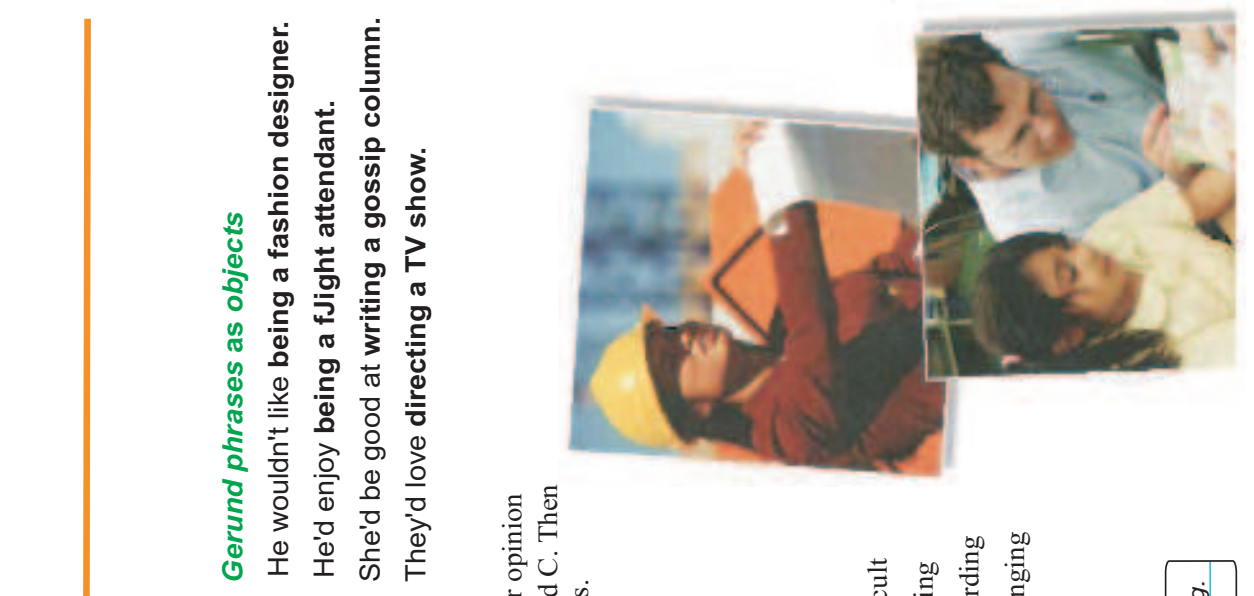

.ี ฮี

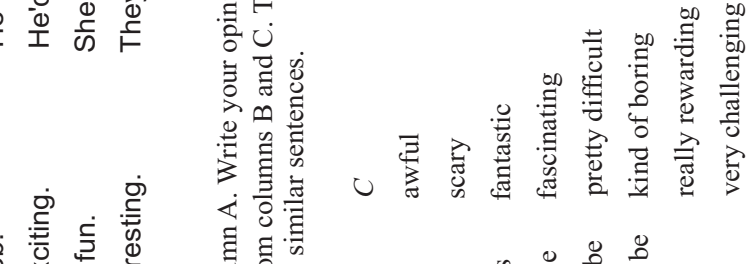

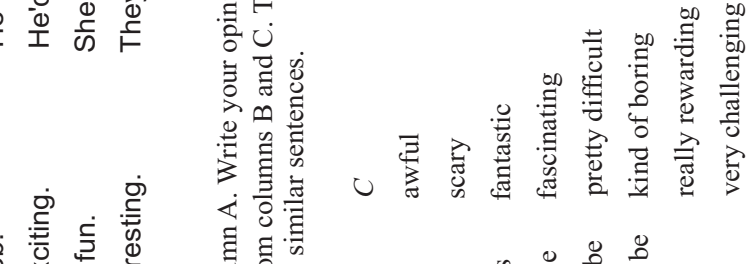

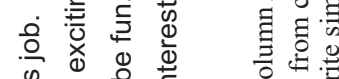

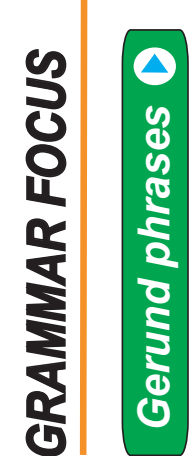

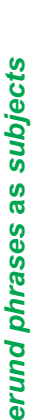

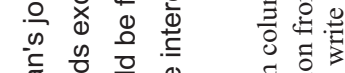

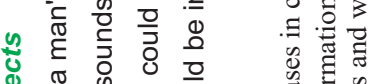

๑)

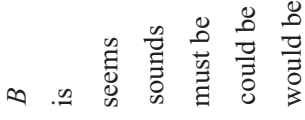

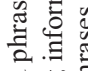

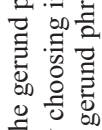

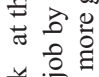

产 $\frac{0}{0}$

4.

$(\rightarrow)$
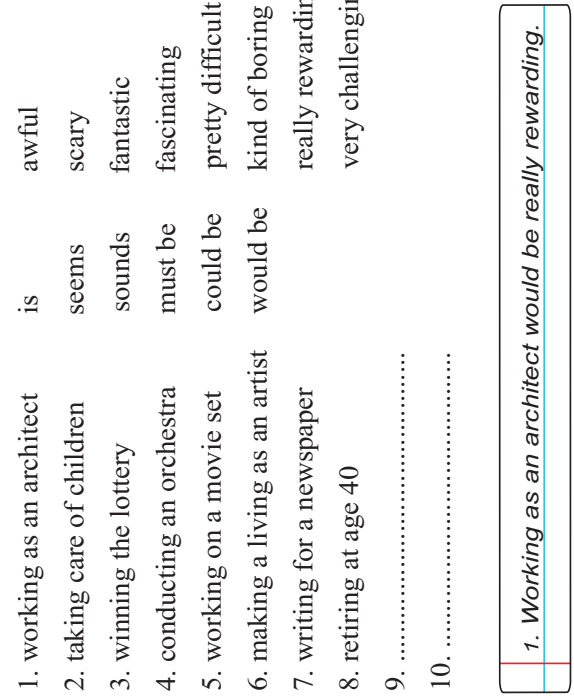


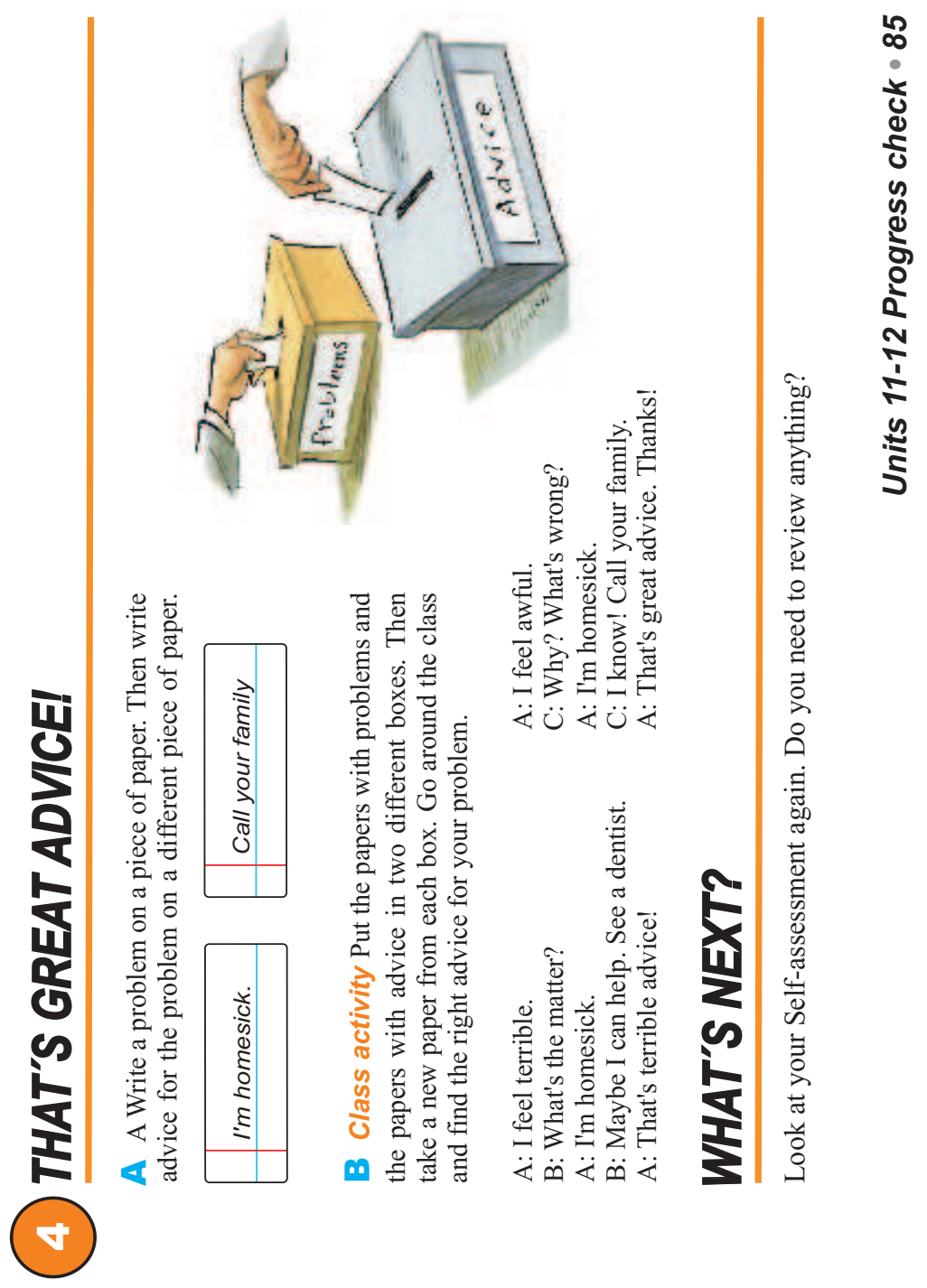




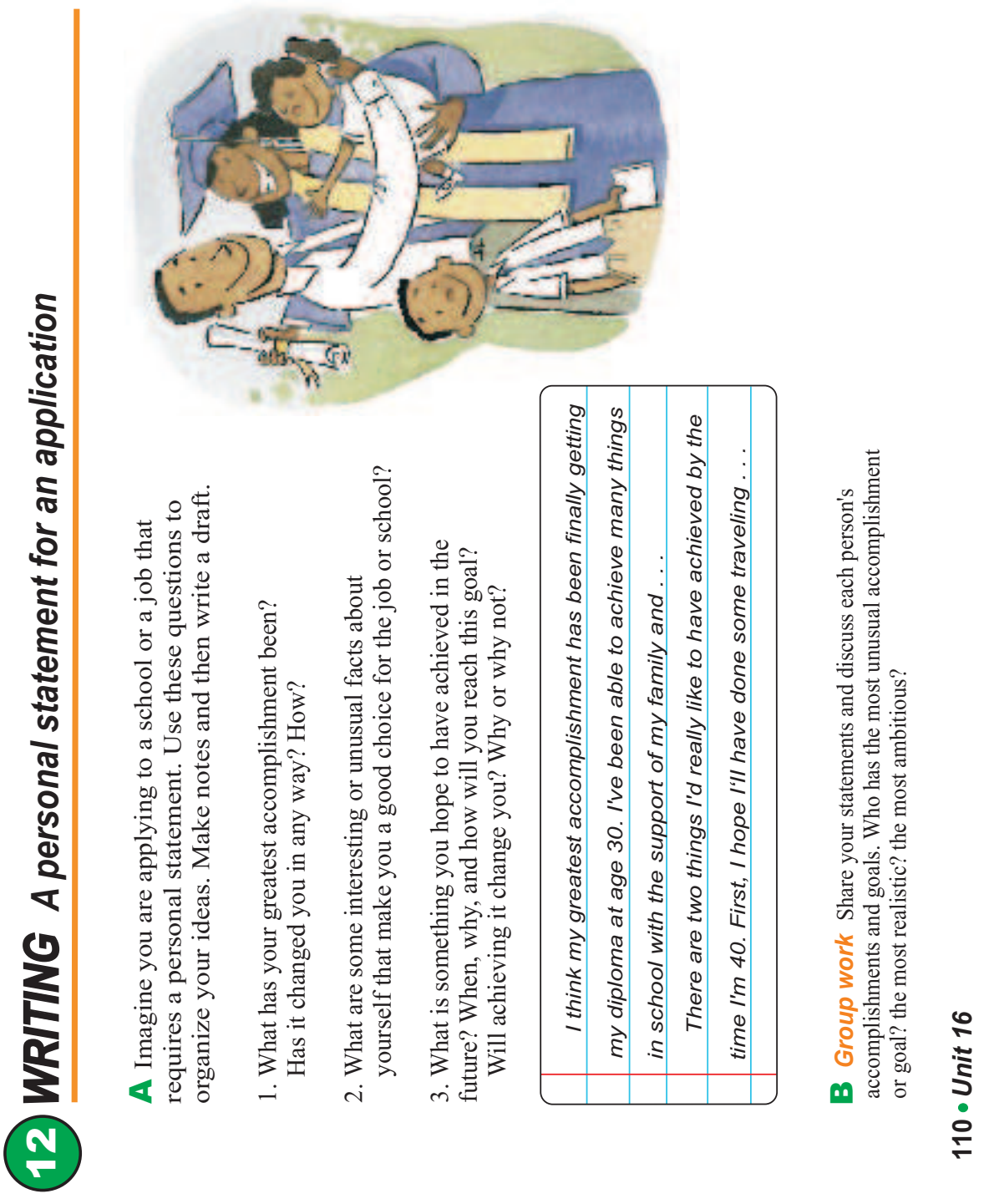


